\title{
Polymorphisms in IL-10 and TGF- $\beta$ gene promoter are associated with lower risk to gastric cancer in a Mexican population
}

\author{
Cecilia Martínez-Campos ${ }^{1 \dagger}$, Kirvis Torres-Poveda ${ }^{2,3+}{ }^{\dagger}$, Margarita Camorlinga-Ponce ${ }^{4}$, Lourdes Flores-Luna ${ }^{5}$, \\ Carmen Maldonado-Bernal ${ }^{6}$, Vicente Madrid-Marina ${ }^{2 *}$ and Javier Torres ${ }^{4^{*}}$
}

\begin{abstract}
Background: Helicobacter pylori infection is recognized as the main risk factor for gastric cancer (GC), the fifth most common neoplasia worldwide. H. pylori interacts with the immune system, disrupting the cytokine network and inducing chronic inflammation. This work aimed to evaluate the association between single nucleotide polymorphisms (SNPs) in selected cytokine gene promoters and GC.

Methods: The study included 359 subjects, 125 GC patients, 109 intestinal metaplasia (IM) patients and 125 asymptomatic controls. DNA was extracted from white blood cells and nine SNPs in cytokine gene promoters were genotyped using predesigned 5'-endonulease assays. The association of the SNPs with IM and GC was evaluated using multinomial regression models.
\end{abstract}

Results: Both genotypes, $T C(O R=0.51,95 \% \mathrm{Cl}=0.27-0.98)$ and $\Pi(O R=0.42,95 \% \mathrm{Cl}=0.20-0.91)$ in the locus -509 of the TGF- $\beta$ promoter were significantly associated with GC. The $\Pi$ genotype in the locus -819 of the $/ L-10$ promoter was also significantly associated with $\mathrm{GC}(O R=0.37,95 \% \mathrm{Cl}=0.17-0.81)$. No significant association was found with SNPs IL-4 -590 T/C (rs1800629), IL-6 -573G/C (rs1800796), IL-10 -592C/A (rs1800872), IL-10 -1082A/G (rs1800896), and, IFN- $\gamma-1615 C / T$ (rs2069705).

Conclusions: SNPs in TGF $\beta$ (- 509 C/T, rs1800469) and IL-10 (-819 C/T, rs1800871) promoters were associated with a lower risk for GC in a Mexican population.

Keywords: Single nucleotide polymorphism, Cytokines, H, Pylori, Gastric cancer

\section{Background}

Gastric cancer (GC) is the fifth most common cancer type and the third leading cause of death by cancer worldwide [1]. The highest estimated mortality rates occur in Eastern Asia, Eastern Europe, and Central and South America [1], where cases usually seek medical attention at later stages when prognosis is very poor. In Mexico, GC is the sixth most common cancer after

\footnotetext{
* Correspondence: vmarina@insp.mx; jtorres157@yahoo.com.mx

${ }^{\dagger}$ Cecilia Martínez-Campos and Kirvis Torres-Poveda contributed equally to this work as first coauthors of this manuscript.

${ }^{2}$ Dirección de Infecciones Crónicas y Cáncer. Centro de Investigación sobre Enfermedades Infecciosas, Instituto Nacional de Salud Pública, Cuernavaca, Morelos, Mexico

${ }^{4}$ Unidad de Investigación en Enfermedades Infecciosas, UMAE Pediatría, CMN S-XXI, IMSS, Mexico City, Mexico

Full list of author information is available at the end of the article
}

breast, prostate, cervix uteri, colorectal, and lung cancer, and represents the fifth cause of cancer deaths.

While several socio-demographic and environmental risk factors have been associated with $\mathrm{GC}$, infection by Helicobacter pylori is recognized as the main risk factor [2], as it is classified as a group I carcinogen by the IARC (International Agency for Research on Cancer) [3]. Prevalence of H. pylori in countries with high GC incidence ranges from 31 to $73 \%$ in the general population, and from 11 to $66.2 \%$ in children [4].

The most widely accepted mechanism by which $H$. pylori contributes to carcinogenesis is the induction of a chronic and dysregulated inflammation; the immune response against this gram-negative bacterium may also contribute to its pathogenesis. The attachment of $H$. pylori to the gastric epithelial cells induces the release of 
inflammatory cytokines that recruit and activate $\mathrm{T}$ lymphocytes, macrophages, and plasma cells [5]. Cytokines have pleiotropic effects on immune and epithelial cells, regulating cell proliferation and differentiation and modulating the secretion of other cytokines and the type and degree of inflammation. A chronic long-lasting dysregulated inflammation in the gastric mucosa is recognized as the main driving mechanism to cause tissue and DNA damage that may lead to gastric cancer.

$H$. pylori infection is often acquired in childhood and colonization of the gastric epithelium promotes an upregulation of TLR-2, $-4,-5$, and -9 , and the expression of cytokines such as IL-1, IL-6, IL-8, TNF- $\alpha$, IFN- $\gamma$, TGF- $\beta$, and IL-10 [6]. The type and amount of cytokines produced in response to $H$. pylori infection have a significant impact on the risk of developing GC. This may depend on the kind of cytokines released by different subsets of differentiated $\mathrm{CD}^{+}$helper $\mathrm{T}$ cells in response to $H$. pylori. The pattern of cytokines secreted by the $\mathrm{T}$ helper (Th) cells will vary depending on the subsets cells; Th1 cells secretes IFN- $\gamma$, whereas Th2, secretes IL4, IL-6, and IL-10. Th3 secretes TGF- $\beta$, Th17 secretes IL-17A and IL-22 and Th22 secretes IL-22 [7]. Accordingly, cytokines are obvious candidates to be studied as GC risk factors, and polymorphisms in several cytokine genes may influence the risk for GC.

Considering that cancer is a disease with a multifactorial origin and that GC is characterized by a disruption of the cytokine network induced by $H$. pylori, we hypothesized that some SNPs in cytokine gene promoters might be associated with the risk to intestinal metaplasia (IM) and GC.

\section{Methods}

\section{Population under study}

The population under study was selected as previously described [8], and similar procedures were followed for sample collection. Briefly, the population was selected from patients over 30 years of age seeking attention because of gastroduodenal symptoms at the Hospital de Oncología, Centro Médico Siglo XXI, Instituto Mexicano del Seguro Social (IMSS), and Instituto Nacional de Cancerología, Secretaría de Salud, Mexico City. Diagnosis was based on endoscopic examination and confirmed by histopathology studies, and patients with confirmed IM or GC diagnosis were invited to participate. Exclusion criteria were: patients under treatment for cancer or being administered with antibiotics, bismuth compounds, proton-pump inhibitors, or nonsteroidal anti-inflammatory drugs for at least 2 weeks prior to the study. The control group included healthy blood donors without any symptom or medication attending the blood bank of the Centro Médico Siglo XXI, IMSS, Mexico City. Ethics committees from IMSS and Secretaría de Salud, México, approved the study. Those patients who agreed to participate in this study were required to read and sign an informed consent letter.

This cross-sectional study included all cases of IM (109 patients) and GC (126 patients) available at our sample's bank that fulfilled inclusion criteria; a similar number of consecutive volunteers (125 healthy controls) attending the blood bank were recruited. Controls were blood donor without any symptom or medication attending the blood bank of the Centro Médico Siglo XXI, IMSS, Mexico City. The exclusion criterion was to have any illness that requires medication. We were unable to strictly match cases and controls by age because the blood donors have to be younger than 45 years of age.

All GC cases were distal cancers, located in the antrum and/or corpus, about 50\% type diffuse, 30\% type intestinal and $20 \%$ mixed; almost $70 \%$ of the cases were in stage III or IV.

\section{Samples}

Seven gastric biopsies were taken from each patient, and final diagnosis was defined by the most severe lesion found in any of the biopsies. Blood samples $(10 \mathrm{~mL})$ were obtained by venous puncture; peripheral blood mononuclear cells (PBMCs) were purified by centrifugation in a Ficoll-Hypaque density gradient. DNA was isolated from these cells using the QIAamp DNA Blood Mini Kit (QIAgen) and frozen at $-70{ }^{\circ} \mathrm{C}$ until tested for SNPs in cytokine promoter regions.

\section{Determination of $H$. pylori infection}

Enzyme-linked immunosorbent assays (ELISA) were performed to detect IgG anti-whole $H$. pylori extract antibodies, and IgG anti-CagA protein antibodies, using ELISA tests validated in our population with a sensitivity of $85 \%$ and specificity of $87 \%$, as previously described [9]. H. pylori infection was confirmed by histology studies after staining tissues of all biopsies with Giemsa and H\&E.

\section{SNP selection and genotyping}

The SNPs to be analyzed were selected according to the following criteria: 1) SNPs were validated by frequency or utilization in the HAPmap Project; 2) SNPs are in the promoter region and have a potential role in transcriptional regulation of the cytokine evaluated (as assessed by the Ensembl browser); 3) SNPs are in IL-4, IL-6, IL-10, TGF- $\beta$, TNF- $\alpha$ and IFN- $\gamma$ promoter regions, in the binding sites of transcription factors that potentially influence transcriptional activity, as reported in Biomart.URL: https://www. ensembl.org/biomart/martview/01e2037218528c76d67d2a5 fde286d0c. The polymorphisms $I L-4-590 \mathrm{C} / \mathrm{T}$ (rs2243250), IL-6 -573G/C (rs1800796), IL-10 -592C/A (rs1800872), $I L-10 \quad-819 \mathrm{C} / \mathrm{T} \quad(\mathrm{rs} 1800871), \quad I L-10 \quad-1082 \mathrm{~A} / \mathrm{G}$ (rs1800896), TGF- $\beta-509 \mathrm{C} / \mathrm{T}$ (rs1800469), TGF- $\beta$-800G/A 
(rs1800468), TNF- $\alpha$-308G/A (rs1800629), and IFN- $\gamma-$ 1615C/T (rs2069705) were selected. A 20-ng sample of genomic DNA was genotyped using predesigned 5 '-endonulease assays (Taqman, Applied Biosystems, Waltham, MA) in a 96-well StepOnePlus ${ }^{\text {Tu }}$ instrument, according to manufacturer's directions. For quality control purposes, a call rate of 0.99 was used for all samples. Ten percent of the samples studied were randomly selected and reanalyzed to validate the results.

\section{Statistical analysis}

Descriptive variables were analyzed by the Chi-square test; continuous variables were expressed as mean \pm standard deviation (SD); and categorical variables were described as percent of the total. Hardy-Weinberg equilibrium models in controls were determined for all SNPs. The risk or protection level for genotypes and alleles was determined as odds ratios (OR) and 95\% confidence intervals $(95 \% \mathrm{CI})$. The association between SNPs and IM or GC was evaluated estimating OR values with multinomial logistic regression models. All statistical analyses were performed using the software Stata/SE v.14 (STATA, Inc., College Station, TX); $P$ values $<0.05$ were considered as statistically significant.

\section{Results}

Socio-demographic and clinical data of IM and GC patients and control subjects are shown in Table 1. Age, sex, history of alcohol consumption, education level, $H$. pylori infection, and CagA detection were different in IM and GC patient groups with respect to controls. On average, IM and GC patients were older than controls. Also, the proportion of females was higher in IM (65\%) and GC (59\%) groups than in controls (40\%). The proportion of alcohol consumers was higher in controls (70\%) than in GC (50\%) patients; furthermore, a significant association between alcohol consumption and protection from $\mathrm{GC}$ was found $(\mathrm{OR}=0.44$, 95\% CI 0.31-0.64, $P=0.001$ ). In IM patients $H$. pylori infection and CagA antibodies were detected in 83.5 and $78 \%$, respectively. In contrast, in the GC group $58.7 \%$ were positive for $\mathrm{H}$. pylori and $53.2 \%$ for CagA.

Table 1 General characteristics of the population under study

\begin{tabular}{|c|c|c|c|c|c|}
\hline Variable & Control & Metaplasia & $P$-value & Gastric cancer & $P$-value \\
\hline Age & $n=125$ & $n=109$ & & $n=125$ & \\
\hline Years (SD) & $34(11.4)$ & 57.62 & 0.0001 & $59(12.2)$ & 0.0001 \\
\hline $\operatorname{Sex}(n, \%)$ & $n=125$ & $n=109$ & & $n=125$ & \\
\hline Female & $50(40)$ & $71(65.14)$ & 0.0001 & $74(59.2)$ & 0.002 \\
\hline Male & $75(60)$ & $38(34.86)$ & & $51(40.8)$ & \\
\hline Smoking status (n, \%) & $n=125$ & $n=109$ & 0.576 & $n=125$ & \\
\hline None & $79(63.2)$ & $65(59.63)$ & & $74(59.2)$ & 0.51 \\
\hline Smoker & $46(36.8)$ & $44(40.37)$ & & $51(40.8)$ & \\
\hline Alcohol consumption (n, \%) & $n=125$ & $n=109$ & & $n=125$ & \\
\hline No & $38(30.52)$ & $66(60.5)$ & 0.0001 & $62(49.6)$ & 0.002 \\
\hline Regular & $87(69.6)$ & $43(39.45)$ & & $63(50.4)$ & \\
\hline Education, years (n, \%) & $n=125$ & $n=109$ & & $n=123$ & \\
\hline$>12$ & $55(44)$ & $1(0.92)$ & 0.0001 & $10(8.1)$ & 0.0001 \\
\hline $10-12$ & $43(34.4)$ & $7(6.42)$ & & $24(19.5)$ & \\
\hline $0-9$ & $25(20)$ & $101(92.66)$ & & $91(73.9)$ & \\
\hline H. pylori (n, \%) & $n=123$ & $n=109$ & & $n=126$ & \\
\hline Negative & $69(56)$ & $18(16.51)$ & 0.0001 & $52(41.3)$ & 0.01 \\
\hline Positive & $54(44)$ & 91 (83.49) & & $74(58.7)$ & \\
\hline CagA $(n, \%)$ & $n=125$ & $n=109$ & & $n=126$ & \\
\hline Negative & $85(68)$ & $24(22.02)$ & 0.0001 & $59(46.8)$ & 0.001 \\
\hline Positive & $40(32)$ & $85(77.98)$ & & $67(53.2)$ & \\
\hline Family history of gastric cancer (n, \%) & $n=125$ & & & $n=125$ & \\
\hline No & $119(95.2)$ & - & - & $106(84.8)$ & 0.006 \\
\hline Yes & $6(4.8)$ & - & & $19(15.2)$ & \\
\hline
\end{tabular}

Values in bold indicate significant differences $(P<0.05)$

$X^{2}$ test $P$-value 
Nine cytokine polymorphisms were genotyped and the association of these SNPs with IM and GC was evaluated by multinomial regression analysis. All SNPs matched with a Hardy-Weinberg equilibrium model in controls. SNPs TNF- $\alpha-308 \mathrm{G} / \mathrm{A}$ (rs1800629) and TGF- $\beta$ -800G/A (rs1800468) were not polymorphic in the population under study. No significant association with IM or GC was found with the following SNPs: $I L-4$ 590 T/C (rs1800629), IL-6 -573G/C (rs1800796), IL-10 592C/A (rs1800872), IL-10 -1082A/G (rs1800896), and IFN- $\gamma-1615 \mathrm{C} / \mathrm{T}$ (rs2069705). However, there was a trend toward a significant association of the genotypes CT in the SNP $I L-4-590 \mathrm{~T} / \mathrm{C}$ with $\mathrm{IM}(\mathrm{OR}=0.50,95 \%$ CI $0.24-1.06, P=0.07)$ and the AA genotype in the IL-10 -592C/A with GC (OR $=0.51,95 \%$ CI $0.24-1.09$, $P=0.08)$ (Table 2).

The genotype TT at the position -819 of the $I L-10$ (rs1800871) gene promoter was significantly associated with a reduction of over $60 \%$ in the risk for GC (Table 2). Furthermore, the association analysis showed that allele $\mathrm{T}$ of rs1800871 was significantly associated with a protection for $\mathrm{GC}(\mathrm{OR}=0.63,95 \% \mathrm{CI} 0.43-0.91, P=0.014$; power $=$ $0.64)$.

On the other hand, the CT genotype in the TGF- $\beta-$ $509 \mathrm{C} / \mathrm{T}$ (rs1800469) polymorphism was significantly associated with a reduction of almost $50 \%$ in the risk for GC, whereas the TT genotype was strongly associated with a reduction of about $60 \%$ for GC (Table 2). In agreement with this result, the allele $\mathrm{T}$ of rs1800469 was associated with a decreased risk for GC (OR $=0.64,95 \%$ CI 0.44-0.94, $P=0.023$; power $=0.99$ ).

\section{Discussion}

The chronic infection by $H$. pylori promotes an inflammatory environment that may disrupts the homeostasis in the gastric mucosa. This unbalanced inflammatory response may lead to increased cell proliferation and transformation, or to DNA damage. The study of genetic variants in proinflammatory and immunosuppressive cytokine genes therefore might help explain why only a small fraction (less than 2\%) of individuals infected with H. pylori develop GC. This work aimed to evaluate the association of cytokine gene promoter SNPs with IM and GC in a Mexican population.

Regarding the general characteristics of the population studied, we found that alcohol consumption was associated with protection for GC. However, the association between alcohol consumption and GC is still controversial. For instance, some prospective studies have reported an increased risk for GC in alcohol consumers while other studies have reported a lack of association [10-12]. Similarly, meta-analyses studies have reported either an increased risk for GC associated to alcohol consumption or no association [13-15].
The observed frequency of SNPs TNF- $\alpha-308 \mathrm{G} / \mathrm{A}$ and TGF $\beta-800 \mathrm{G} / \mathrm{A}$ showed that these SNPs are not polymorphic in the population under study, in accordance with previous reports which have found that TNF- $\alpha$ -308G/A is not polymorphic in Mexican nor in Honduran populations [16-18]. On the other hand, the SNP $T G F-\beta-800 \mathrm{G} / \mathrm{A}$ has been less studied and our work is the first report in a Mexican population. Our data showed a borderline association of the genotype CT (SNP IL-4 $-590 \mathrm{~T} / \mathrm{C})$ with precancerous IM $(\mathrm{OR}=0.50$, 95\% CI 0.23-1.05, $P=0.06$; Table 2). Other studies have evaluated the association of SNP IL-4 $-590 \mathrm{~T} / \mathrm{C}$ with precancerous lesions and GC in a Venezuelan and a Chinese populations, but found no significant association of this SNP with GC $[19,20]$.

Our results showed that subjects carrying the genotype TT in the locus -509 of the TGF- $\beta$ gene had a decreased risk for GC (Table 2). Our result is consistent with a recent meta-analysis, which also found that TT genotype at the locus -509 of the TGF- $\beta$ gene was protective for GC in an Asian population [21], as well as with other studies [22, 23]. In contrast, this TT genotype has been reported as a risk genotype for $\mathrm{GC}$ in an Indian and a Chinese population [24, 25]. The transcription factor AP1 containing JunD regulates the expression of TGF- $\beta$ by binding to the allele $C$ in the locus -509 of the promoter and repressing its expression [26]. Thus, the TT genotype would affect this mechanism of repression favoring TGF- $\beta$ overexpression. Guo et al. (2011) reported that TGF- $\beta$ serum levels were higher in GC patients carrying the TT -509 genotype than in patients with the CC genotype [27]. Furthermore, other studies have reported an increased expression of TGF- $\beta$ in gastric tissue and serum from patients with $\mathrm{GC}$, when compared with subjects with a normal gastric mucosa $[28,29]$. TGF- $\beta$ is an immunosuppressive cytokine that inhibits the cell proliferation and controls inflammation $[30,31]$, which could explain the role of the genotype TT as a protective factor for GC. However, as the disease progresses and, in combination with other cytokines, TGF- $\beta$ could exert a negative effect inducing the loss of cell polarity, cell migration, and angiogenesis, favoring metastasis [32-34].

In the current study we found that the genotype TT in the locus -819 of $I L-10$ was significantly associated with a decreased risk for GC. In agreement with our findings, a meta-analysis reported that genotype TT in the locus -819 of the $I L-10$ gene was associated with an overall reduced risk for GC in an Asian population [35]. Another meta-analysis covering 73 studies also in Asian populations, found the same association [36]. Conversely, a study including 234 advanced GC patients and 243 controls in a Chinese population showed no significant association of the SNP $I L-10-819 \mathrm{C} / \mathrm{T}$ 
Table 2 Association of cytokine gene promoter SNPs with gastroduodenal diseases

\begin{tabular}{|c|c|c|c|c|c|c|}
\hline \multicolumn{7}{|l|}{ IFN- $\gamma-1615 C / T$ (rs2069705) } \\
\hline \multirow[b]{2}{*}{ Studied groups (No. of patients) } & \multirow{2}{*}{$\begin{array}{l}\mathrm{CC}^{\mathrm{a}} \\
\mathrm{N}(\%)\end{array}$} & \multicolumn{2}{|l|}{$\mathrm{CT}$} & \multicolumn{2}{|l|}{$\pi$} & \multirow[t]{2}{*}{$P$-value ${ }^{\dagger}$} \\
\hline & & N (\%) & OR $(95 \% \mathrm{Cl})$ & N (\%) & OR $(95 \% \mathrm{Cl})$ & \\
\hline Control & $54(43.20)$ & $60(48)$ & 1 & $11(8.80)$ & 1 & \\
\hline Intestinal Metaplasia & $8(72.73)$ & $2(18.18)$ & $0.29(0.06-1.50)$ & $1(9.09)$ & $0.64(0.06-6.60)$ & 0.142 \\
\hline Gastric cancer & $59(52.21)$ & 49(43.36) & $0.81(0.47-1.40)$ & $5(4.42)$ & $0.39(0.12-1.22)$ & 0.225 \\
\hline \multicolumn{7}{|l|}{ IL-4-590C/T (rs2243250) } \\
\hline & $C C^{\mathrm{a}}$ & $C T$ & & $\pi$ & & $P$-value ${ }^{\dagger}$ \\
\hline Studied groups (No. of patients) & N (\%) & N (\%) & OR $(95 \% \mathrm{Cl})$ & N (\%) & OR $(95 \% \mathrm{Cl})$ & \\
\hline Control & $31(24.8)$ & $67(53.6)$ & 1 & $27(21.6)$ & 1 & \\
\hline Intestinal Metaplasia & $32(34.4)$ & $29(31.2)$ & $0.50(0.24-1.06)$ & $32(34.4)$ & $1.04(0.47-2.32)$ & 0.004 \\
\hline Gastric cancer & $28(22.6)$ & $53(42.74)$ & $0.90(0.47-1.72)$ & $43(34.68)$ & $1.69(0.82-3.48)$ & 0.066 \\
\hline \multicolumn{7}{|l|}{ IL-6 -573G/C (rs1800796) } \\
\hline & $\mathrm{GG}^{\mathrm{a}}$ & GC & & CC & & $P$-value ${ }^{\dagger}$ \\
\hline Studied groups (No. of patients) & N (\%) & N (\%) & OR $(95 \% \mathrm{Cl})$ & N (\%) & OR $(95 \% \mathrm{Cl})$ & \\
\hline Control & 49(40.16) & $58(47.54)$ & 1 & $15(12.30)$ & 1 & \\
\hline Intestinal Metaplasia & $39(41.49)$ & $41(43.62)$ & $0.89(0.46-1.73)$ & 14(14.89) & $1.25(0.46-3.37)$ & 0.791 \\
\hline Gastric cancer & 49(40.16) & $55(45.08)$ & $0.96(0.55-1.68)$ & $18(14.75)$ & $1.49(0.65-3.45)$ & 0.838 \\
\hline \multicolumn{7}{|l|}{ IL-10 -592C/A (rs1800872) } \\
\hline & $C C^{a}$ & CA & & AA & & $P$-value ${ }^{\dagger}$ \\
\hline Studied groups (No. of patients) & N (\%) & N (\%) & OR $(95 \% \mathrm{Cl})$ & N (\%) & OR $(95 \% \mathrm{Cl})$ & \\
\hline Control & $34(27.20)$ & $61(48.80)$ & 1 & $30(24.00)$ & 1 & \\
\hline Intestinal Metaplasia & $30(28.04)$ & 47(43.93) & $0.70(0.34-1.44)$ & $30(28.04)$ & $0.96(0.42-2.16)$ & 0.715 \\
\hline Gastric cancer & 39(31.71) & $64(52.03)$ & $0.85(0.47-1.56)$ & $20(16.26)$ & $0.51(0.24-1.09)$ & 0.301 \\
\hline \multicolumn{7}{|l|}{ IL-10-819C/T (rs1800871) } \\
\hline & $\mathrm{CC}^{\mathrm{a}}$ & $C T$ & & $\pi$ & & $P$-value ${ }^{\dagger}$ \\
\hline Studied groups (No. of patients) & N (\%) & N (\%) & OR $(95 \% \mathrm{Cl})$ & N (\%) & OR $(95 \% \mathrm{Cl})$ & \\
\hline Control & $33(27.05)$ & $60(49.18)$ & 1 & $29(23.77)$ & 1 & \\
\hline Intestinal Metaplasia & $32(32.32)$ & $45(45.45)$ & $0.70(0.34-1.42)$ & $22(22.22)$ & $0.70(0.30-1.63)$ & 0.693 \\
\hline Gastric cancer & $44(35.48)$ & $63(50.81)$ & $0.71(0.39-1.29)$ & $17(13.71)$ & $0.37(0.17-0.81)$ & 0.093 \\
\hline \multicolumn{7}{|l|}{ IL-10 -1082A/G (rs1800896) } \\
\hline & $A A^{a}$ & AG & & GG & & $P$-value ${ }^{\dagger}$ \\
\hline Studied groups (No. of patients) & N (\%) & N (\%) & OR $(95 \% \mathrm{Cl})$ & N (\%) & OR $(95 \% \mathrm{Cl})$ & \\
\hline Control & $68(55.28)$ & $44(35.77)$ & 1 & $11(8.94)$ & 1 & \\
\hline Intestinal Metaplasia & $62(59.62)$ & $34(32.69)$ & $0.89(0.47-1.69)$ & $8(7.69)$ & $1.14(0.36-3.57)$ & 0.8 \\
\hline Gastric cancer & $62(49.60)$ & $54(43.20)$ & $1.34(0.78-2.32)$ & $9(7.20)$ & $1.19(0.44-3.19)$ & 0.477 \\
\hline \multicolumn{7}{|l|}{ TGF- $\beta$-509C/T (rs1800469) } \\
\hline & $\mathrm{CC}^{\mathrm{a}}$ & $\mathrm{CT}$ & & $\pi$ & & $P$-value ${ }^{\dagger}$ \\
\hline Studied groups (No. of patients) & N (\%) & N (\%) & OR $(95 \% \mathrm{Cl})$ & N (\%) & OR $(95 \% \mathrm{Cl})$ & \\
\hline Control & $25(21.74)$ & $60(52.17)$ & 1 & $30(26.09)$ & 1 & \\
\hline Intestinal Metaplasia & $17(28.80)$ & 23(39.00) & $0.52(0.21-1.31)$ & 19(32.20) & $0.66(0.24-1.77)$ & 0.25 \\
\hline Gastric cancer & $41(34.45)$ & $54(45.38)$ & $0.51(0.27-0.98)$ & $24(20.17)$ & $0.42(0.20-0.91)$ & 0.091 \\
\hline
\end{tabular}

Comparisons were made using the asymptomatic group as reference

Adjusted by $H$. pylori infection and sex. Values in bold indicate significant differences $(P<0.05)$

${ }^{\dagger} X^{2}$ test $P$-value

${ }^{a}$ Ancestral genotype was used as reference category 
with GC [37]. The mechanism by which the SNP IL-10 $-819 \mathrm{C} / \mathrm{T}$ could modulate IL-10 expression has not been elucidated, however, a study found that TT genotype was associated with a lower circulating IL-10 expression in comparison with genotypes $\mathrm{CT}$ and $\mathrm{CC}$ in Leishmania Braziliensis-infected patients; in this context, IL-10 was produced by monocytes and CD $4+\mathrm{CD} 25+\mathrm{T}$ lymphocytes [38].

In addition, we found trend for significant association of the genotype AA (SNP IL-10 -592C/A) with GC, which was consistent with the results of Sicinschi et al., who reported that the CC genotype was a risk factor for $\mathrm{GC}$ in a Mexican population [39]. The functional analysis of SNP - 592 C/A suggested that IL-10 expression is regulated by the binding of $\mathrm{Sp} 1$ and $\mathrm{Sp} 3$ transcription factors to the upstream region of this polymorphism. One $\mathrm{C}$ to A change decreased the inhibitory effect of Sp1/Sp3 complex, favoring IL-10 expression in monocyte, B and T human cell lines [40]. Importantly, authors denoted that the activation or repression of $I L-10$ was dependent on the interaction of Sp1 with other transcription factors and the expression levels of these factors.

Haplotype analyses of the IL-10 SNPs have also shown a role in regulating the IL-10 expression. A number of studies have reported that haplotype ATA (IL-10 - 592A/- 819 $T /-1082 A)$ is related to lower IL-10 promoter transcriptional activity and lower IL-10 production in comparison to the haplotype GCC [41-43]. H. pylori-infected patients with chronic gastritis carrying the GCC haplotype exhibited higher IL-10 mucosal expression levels than ATA carriers and this correlated with a higher prevalence of virulent cagA+/vacAs1+/babA2+ H pylori strains [44]. In line with these results, the GCC haplotype was significantly associated with an increased risk for GC in comparison with ATA haplotype in Japanese, Taiwanese and Chinese populations $[37,45,46]$. In addition, elevated serum IL-10 levels have been detected in GC patients when compared with those in controls and high circulating IL-10 levels have been associated with a worse prognosis [47-49]. Taken together, these results suggest that IL-10 -819TT and -592AA genotypes are associated with a decreased risk for GC by maintaining a low expression of IL-10, which could then favor the APC's access to the tumor cells and the infiltration of CD8 + T lymphocytes [50].

We are aware of some limitations of our study; first, the sample size was not large enough resulting in a decreased power of the study, which probably masked the association of other SNPs with GC. Even though, it allowed us to identify SNPs significantly associated with GC. Additionally, we tested a reduced number of SNPs in cytokine gene promoter regions, which precludes a comprehensive study of the association of SNPs in regions other than promoters with GC. Another limitation of the study is that we did not match by age GC cases and healthy controls. This is because in our institution blood donors have to be less than 45 years of age, whereas GC usually occurs at later ages. Still, we should notice that in Mexico the incidence rate for GC in the population is less than 10 in 100,000, so that the probability that one of these 125 asymptomatic adults develop $\mathrm{GC}$ is extremely low.

In summary, our results showed that the SNPs TGF- $\beta \quad-509 \mathrm{C} / \mathrm{T} \quad$ (rs1800469) and $I L-10 \quad-819 \mathrm{C} / \mathrm{T}$ (rs1800871) were associated with a reduced risk for $\mathrm{GC}$ in a Mexican population. Interestingly, the same SNPs, $I L-10-809 \mathrm{~T} / \mathrm{C}$ and TGF- $\beta-509 \mathrm{~T} / \mathrm{C}$, were associated with an increased risk for cervical cancer in a Mexican and Asian population [36,51], which is consistent with the biological differences in the natural history of cervical and gastric cancer, specifically the role of inflammatory mediators in each pathology. Further studies are required to evaluate the role of these SNPs in regulating the expression of TGF- $\beta$ and IL-10 during GC progression.

\section{Abbreviations}

GC: Gastric cancer; IM: Intestinal metaplasia; SNP: Single Nucleotide Polymorphism

\section{Acknowledgements}

The authors want to thank the patients who kindly agreed to participate in this study. The authors wish to thank Juraj Lord for manuscript assistance.

\section{Funding}

This study was funded by the Instituto Nacional de Salud Pública, Mexico, and the Consejo Nacional de Ciencia y Tecnología (MX), grants CONACyTFONSEC SSA/IMSS/ISSSTE-2008-C01-87701, CONACYT-FONSEC SSA/IMSS/ ISSSTE-2014-C01-234191, and CONACyT-Fondo Apoyos complementarios para la adquisición de equipo científico 2013-205707, Mexico.

\section{Availability of data and materials}

The datasets used and/or analyzed during the current study are available from the corresponding author on reasonable request.

\section{Authors' contributions}

VMM, JT and KTP conceived and designed the present study. CMC and KTP conducted the experiments; CMC analyzed data and wrote the manuscript: CMB recruited and collected the clinical data of patients; MCP and LFL carried out DNA extraction. All authors critically read and approved the final manuscript.

\section{Ethics approval and consent to participate}

The patients who accepted to participate in this study were asked to sign an informed consent form. Ethics committees from IMSS and Secretaría de Salud, México, approved the study.

\section{Consent for publication}

Not applicable. This manuscript does not contain data from any individual person.

\section{Competing interests}

The authors declare that they have no competing interests.

\section{Publisher's Note}

Springer Nature remains neutral with regard to jurisdictional claims in published maps and institutional affiliations.

\section{Author details}

'Department of Molecular Genetics and Microbiology, Duke University Medical Center, Durham, NC, USA. ²Dirección de Infecciones Crónicas y 
Cáncer. Centro de Investigación sobre Enfermedades Infecciosas, Instituto Nacional de Salud Pública, Cuernavaca, Morelos, Mexico. ${ }^{3}$ CONACyT-Instituto Nacional de Salud Pública, Cuernavaca, Morelos, Mexico. ${ }^{4}$ Unidad de Investigación en Enfermedades Infecciosas, UMAE Pediatría, CMN S-XXI, IMSS, Mexico City, Mexico. ${ }^{5}$ Centro de investigación en Salud Poblacional, Instituto Nacional de Salud Pública, Cuernavaca, Morelos, Mexico. 'Laboratorio de Investigación en Inmunología y Proteómica, Hospital Infantil de Mexico Federico Gómez, SS, Mexico City, Mexico.

\section{Received: 3 October 2018 Accepted: 23 April 2019} Published online: 15 May 2019

\section{References}

1. Ferlay J, Soerjomataram I, Dikshit R, Eser S, Mathers C, Rebelo M, Parkin DM, Forman D, Bray F. Cancer incidence and mortality worldwide: sources, methods and major patterns in GLOBOCAN 2012. Int J Cancer. 2015;136(5): E359-86.

2. Helicobacter and Cancer Collaborative Group. Gastric cancer and Helicobacter pylori: a combined analysis of 12 case control studies nested within prospective cohorts. Gut 2001, 49(3):347-353.

3. Schistosomes, liver flukes and Helicobacter pylori. IARC Working Group on the Evaluation of Carcinogenic Risks to Humans. Lyon, 7-14 June 1994. IARC Monogr Eval Carcinog Risks Hum 1994, 61:1-241.

4. Eusebi LH, Zagari RM, Bazzoli F: Epidemiology of Helicobacter pylori infection. Helicobacter 2014, 19 Suppl 1:1-5.

5. Fuccio L, Eusebi LH, Bazzoli F. Gastric cancer, helicobacter pylori infection and other risk factors. World J Gastrointest Oncol. 2(9):342-7.

6. Lagunes-Servin H, Torres J, Maldonado-Bernal C, Perez-Rodriguez M, HuertaYepez S, Madrazo de la Garza A, Munoz-Perez L, Flores-Luna L, RamonGarcia G, Camorlinga-Ponce M. Toll-like receptors and cytokines are upregulated during helicobacter pylori infection in children. Helicobacter. 18(6):423-32.

7. Bockerstett KA, DiPaolo RJ. Regulation of gastric carcinogenesis by inflammatory cytokines. Cell Mol Gastroenterol Hepatol. 2017:4(1):47-53.

8. Pérez-Rodríguez M, Partida-Rodríguez O, Camorlinga-Ponce M, Flores-Luna L, Lazcano E, Gomez A, Herrera-Goepfert R, Medrano-Guzman R, Torres J: Polymorphisms in HLA-DQ genes, together with age, sex, and Helicobacter pylori infection, as potential biomarkers for the early diagnosis of gastric cancer. Helicobacter 2017, 22(1):1-10.

9. Camorlinga-Ponce M, Torres J, Perez-Perez G, Leal-Herrera Y, Gonzalez-Ortiz B, Madrazo de la Garza A, Gomez A, Munoz O. Validation of a serologic test for the diagnosis of helicobacter pylori infection and the immune response to urease and CagA in children. Am J Gastroenterol. 1998;93(8):1264-70.

10. Wang S, Freedman ND, Loftfield E, Hua X, Abnet CC. Alcohol consumption and risk of gastric cardia adenocarcinoma and gastric non-cardia adenocarcinoma: a 16-year prospective analysis from the NIH-AARP diet and health cohort. Int J Cancer. 2018;143(11):2749-57.

11. Everatt $R$, Tamosiunas A, Kuzmickiene I, Virviciute D, Radisauskas $R$, Reklaitiene R, Milinaviciene E. Alcohol consumption and risk of gastric cancer: a cohort study of men in Kaunas, Lithuania, with up to 30 years follow-up. BMC Cancer. 2012;12:475.

12. Minami $Y$, Kanemura $S$, Oikawa $T$, Suzuki $S$, Hasegawa $Y$, Miura $K$, Nishino $Y$, Kakugawa Y, Fujiya T. Associations of cigarette smoking and alcohol drinking with stomach cancer survival: a prospective patient cohort study in Japan. Int J Cancer. 2018;143(5):1072-85.

13. Han $X$, Xiao L, Yu Y, Chen Y, Shu HH. Alcohol consumption and gastric cancer risk: a meta-analysis of prospective cohort studies. Oncotarget. 2017:8(47):83237-45

14. He Z, Zhao TT, Xu HM, Wang ZN, Xu YY, Song YX, Ni ZR, Xu H, Yin SC, Liu $X Y$, et al. Association between alcohol consumption and the risk of gastric cancer: a meta-analysis of prospective cohort studies. Oncotarget. 2017; 8(48):84459-72.

15. Ma K, Baloch Z, He TT, Xia X. Alcohol consumption and gastric Cancer risk: a Meta-analysis. Med Sci Monit. 2017;23:238-46.

16. Partida-Rodriguez O, Torres J, Flores-Luna L, Camorlinga M, Nieves-Ramirez M, Lazcano E, Perez-Rodriguez M. Polymorphisms in TNF and HSP-70 show a significant association with gastric cancer and duodenal ulcer. Int J Cancer. 2010;126(8):1861-8.

17. Garza-Gonzalez E, Bosques-Padilla FJ, El-Omar E, Hold G, Tijerina-Menchaca R, Maldonado-Garza HJ, Perez-Perez Gl. Role of the polymorphic IL-1B, IL-
$1 \mathrm{RN}$ and TNF-A genes in distal gastric cancer in Mexico. Int J Cancer. 2005;114(2):237-41.

18. Morgan DR, Dominguez RL, Keku TO, Heidt PE, Martin CF, Galanko JA, Omofoye OA, Sandler RS. Gastric cancer and the high combination prevalence of host cytokine genotypes and helicobacter pylori in Honduras. Clin Gastroenterol Hepatol. 2006:4(9):1103-11.

19. Kato I, Canzian F, Franceschi S, Plummer M, van Doorn LJ, Lu Y, GioiaPatricola L, Vivas J, Lopez G, Severson RK, et al. Genetic polymorphisms in anti-inflammatory cytokine signaling and the prevalence of gastric precancerous lesions in Venezuela. Cancer causes control. 2006;17(9):1183-91.

20. Pan XF, Wen Y, Loh M, Wen YY, Yang SJ, Zhao ZM, Tian Z, Huang H, Lan H, Chen $F$, et al. Interleukin-4 and -8 gene polymorphisms and risk of gastric cancer in a population in southwestern China. Asian Pac J Cancer Prev. 2014;15(7):2951-7

21. Gu YY, Wang H, Wang S. TGF-beta1 C-509T and T869C polymorphisms and cancer risk: a meta analysis. Int J Clin Exp Med. 2015;8(10):17932-40.

22. Xu L, Zeng Z, Chen B, Wu X, Yu J, Xue L, Tian L, Wang Y, Chen M, Sung JJ, et al. Association between the TGFB1 -509C/T and TGFBR2 -875AVG polymorphisms and gastric cancer: a case-control study. Oncol Lett. 2011;2(2):371-7.

23. Jin G, Wang L, Chen W, Hu Z, Zhou Y, Tan Y, Wang J, Hua Z, Ding W, Shen , et al. Variant alleles of TGFB1 and TGFBR2 are associated with a decreased risk of gastric cancer in a Chinese population. Int J Cancer. 2007;120(6): 1330-5.

24. Li T, Cao BW, Dai Y, Cui H, Yang HL, Xu CQ. Correlation of transforming growth factor beta-1 gene polymorphisms C-509T and T869C and the risk of gastric cancer in China. J Gastroenterol Hepatol. 2008;23(4):638-42.

25. Pavithra D, Gautam M, Rama R, Swaminathan R, Gopal G, Ramakrishnan AS, Rajkumar T. TGFbeta C-509T, TGFbeta T869C, XRCC1 Arg194Trp, IKBalpha C642T, IL4 C-590T genetic polymorphisms combined with socio-economic, lifestyle, diet factors and gastric cancer risk: a case control study in south Indian population. Cancer Epidemiol. 2018;53:21-6.

26. Shah R, Hurley CK, Posch PE. A molecular mechanism for the differential regulation of TGF-beta1 expression due to the common SNP -509C-T (c. -1347 C > T). Hum Genet. 2006;120(4):461-9.

27. Guo W, Dong Z, Guo Y, Chen Z, Yang Z, Kuang G, Shan B. Polymorphisms of transforming growth factor-beta1 associated with increased risk of gastric cardia adenocarcinoma in North China. Int. J. Immunogenet. 2011;38(3):215-24.

28. Ma GF, Miao Q, Zeng XQ, Luo TC, Ma LL, Liu YM, Lian JJ, Gao H, Chen SY. Transforming growth factor-beta1 and -beta2 in gastric precancer and cancer and roles in tumor-cell interactions with peripheral blood mononuclear cells in vitro. PLoS One. 2013;8(1):e54249.

29. Li X, Yue ZC, Zhang YY, Bai J, Meng XN, Geng JS, Fu SB. Elevated serum level and gene polymorphisms of TGF-beta1 in gastric cancer. J Clin Lab Anal. 2008;22(3):164-71.

30. Wan YY, Flavell RA. Yin-Yang' functions of transforming growth factor-beta and T regulatory cells in immune regulation. Immunol Rev. 2007;220:199-213.

31. Siegel PM, Massague J. Cytostatic and apoptotic actions of TGF-beta in homeostasis and cancer. Nat Rev Cancer. 2003;3(11):807-21.

32. Fabregat I, Fernando J, Mainez J, Sancho P. TGF-beta signaling in cancer treatment. Curr Pharm Des. 2014;20(17):2934-47.

33. Fu H, Hu Z, Wen J, Wang K, Liu Y. TGF-beta promotes invasion and metastasis of gastric cancer cells by increasing fascin1 expression via ERK and JNK signal pathways. Acta Biochim Biophys Sin. 2009;41(8):648-56.

34. Lin Y, Kikuchi S, Obata Y, Yagyu K. Serum levels of transforming growth factor beta1 are significantly correlated with venous invasion in patients with gastric cancer. J Gastroenterol Hepatol. 2006;21(2):432-7.

35. Xue H, Lin B, An J, Zhu Y, Huang G. Interleukin-10-819 promoter polymorphism in association with gastric cancer risk. BMC Cancer. 2012;12:102.

36. Yu Z, Liu Q, Huang C, Wu M, Li G. The interleukin $10-819 \mathrm{C} / \mathrm{T}$ polymorphism and cancer risk: a HuGE review and meta-analysis of 73 studies including 15,942 cases and 22,336 controls. Omics. 2013:17(4):200-14.

37. Liu J, Song B, Wang JL, Li ZJ, Li WH, Wang ZH. Polymorphisms of interleukin-10 promoter are not associated with prognosis of advanced gastric cancer. World J Gastroenterol. 2011;17(10):1362-7.

38. Salhi A, Rodrigues V Jr, Santoro F, Dessein H, Romano A, Castellano LR, Sertorio M, Rafati S, Chevillard C, Prata A, et al. Immunological and genetic evidence for a crucial role of IL-10 in cutaneous lesions in humans infected with Leishmania braziliensis. J Immunol. 2008;180(9):6139-48.

39. Sicinschi LA, Lopez-Carrillo L, Camargo MC, Correa P, Sierra RA, Henry RR, Chen J, Zabaleta J, Piazuelo MB, Schneider BG. Gastric cancer risk in a Mexican population: role of helicobacter pylori CagA positive infection and 
polymorphisms in interleukin-1 and -10 genes. Int J Cancer. 2006;118(3): 649-57.

40. Steinke JW, Barekzi E, Hagman J, Borish L. Functional analysis of $-571 \mathrm{IL}-10$ promoter polymorphism reveals a repressor element controlled by sp1. J Immunol. 2004;173(5):3215-22.

41. Crawley E, Kay R, Sillibourne J, Patel P, Hutchinson I, Woo P. Polymorphic haplotypes of the interleukin-10 $5^{\prime}$ flanking region determine variable interleukin-10 transcription and are associated with particular phenotypes of juvenile rheumatoid arthritis. Arthritis Rheum. 1999;42(6):1101-8.

42. Lim S, Crawley E, Woo P, Barnes PJ. Haplotype associated with low interleukin-10 production in patients with severe asthma. Lancet. 1998; 352(9122): 113

43. Edwards-Smith CJ, Jonsson JR, Purdie DM, Bansal A, Shorthouse C, Powell EE. Interleukin-10 promoter polymorphism predicts initial response of chronic hepatitis C to interferon alfa. Hepatology. 1999:30(2):526-30.

44. Rad R, Dossumbekova A, Neu B, Lang R, Bauer S, Saur D, Gerhard M, Prinz C. Cytokine gene polymorphisms influence mucosal cytokine expression, gastric inflammation, and host specific colonisation during helicobacter pylori infection. Gut. 2004;53(8):1082-9.

45. Sugimoto M, Furuta T, Shirai N, Nakamura A, Kajimura M, Sugimura H, Hishida A. Effects of interleukin-10 gene polymorphism on the development of gastric cancer and peptic ulcer in Japanese subjects. J Gastroenterol Hepatol. 2007;22(9):1443-9.

46. Wu MS, Wu CY, Chen CJ, Lin MT, Shun CT, Lin JT. Interleukin-10 genotypes associate with the risk of gastric carcinoma in Taiwanese Chinese. Int $J$ Cancer. 2003:104(5):617-23.

47. De Vita F, Orditura M, Galizia G, Romano C, Infusino S, Auriemma A, Lieto E, Catalano G. Serum interleukin-10 levels in patients with advanced gastrointestinal malignancies. Cancer. 1999;86(10):1936-43.

48. Ikeguchi M, Hatada T, Yamamoto M, Miyake T, Matsunaga T, Fukumoto Y, Yamada Y, Fukuda K, Saito H, Tatebe S. Serum interleukin-6 and -10 levels in patients with gastric cancer. Gastric Cancer. 2009;12(2):95-100.

49. Sanchez-Zauco N, Torres J, Gomez A, Camorlinga-Ponce M, Munoz-Perez L, Herrera-Goepfert R, Medrano-Guzman R, Giono-Cerezo S, Maldonado-Bernal C. Circulating blood levels of IL-6, IFN-gamma, and IL-10 as potential diagnostic biomarkers in gastric cancer: a controlled study. BMC Cancer. 2017;17(1):384

50. Sakamoto T, Saito H, Tatebe S, Tsujitani S, Ozaki M, Ito H, Ikeguchi M. Interleukin-10 expression significantly correlates with minor CD8+ T-cell infiltration and high microvessel density in patients with gastric cancer. Int J Cancer. 2006;118(8):1909-14.

51. Torres-Poveda K, Burguete-Garcia Al, Bahena-Roman M, Mendez-Martinez R, Zurita-Diaz MA, Lopez-Estrada G, Delgado-Romero K, Peralta-Zaragoza O, Bermudez-Morales VH, Cantu D, et al. Risk allelic load in Th2 and Th3 cytokines genes as biomarker of susceptibility to HPV-16 positive cervical cancer: a case control study. BMC Cancer. 2016;16:330.

Ready to submit your research? Choose BMC and benefit from:

- fast, convenient online submission

- thorough peer review by experienced researchers in your field

- rapid publication on acceptance

- support for research data, including large and complex data types

- gold Open Access which fosters wider collaboration and increased citations

- maximum visibility for your research: over $100 \mathrm{M}$ website views per year

At $\mathrm{BMC}$, research is always in progress.

Learn more biomedcentral.com/submissions 